\title{
Least Economic Cost Regional Water Supply Planning - Optimising Infrastructure Investments and Demand Management for South East England's 17.6 Million People
}

\author{
Silvia Padula • Julien J. Harou • \\ Lazaros G. Papageorgiou • Yiming Ji • \\ Mohammad Ahmad • Nigel Hepworth
}

Received: 29 December 2012 / Accepted: 15 July 2013 /

Published online: 26 November 2013

(C) The Author(s) 2013. This article is published with open access at Springerlink.com

\begin{abstract}
This paper presents a deterministic capacity expansion optimisation model designed for large regional or national water supply systems. The annual model selects, sizes and schedules new options to meet predicted demands at minimum cost over a multi-year time horizon. Options include: supply-side schemes, demand management (water conservation) measures and bulk transfers. The problem is formulated as a mixed integer linear programming (MILP) optimisation model. Capital, operating, carbon, social and environmental costs of proposed discrete schemes are considered. User-defined annual water saving profiles for demand management schemes are allowed. Multiple water demand scenarios are considered simultaneously to ensure the supplydemand balance is preserved across high demand conditions and that variable costs are accurately assessed. A wide range of supplementary constraints are formulated to consider the interdependencies between schemes (pre-requisite, mutual exclusivity, etc.). A two-step optimisation scheme is introduced to prevent the infeasibilities that inevitably appear in real applications. The model was developed for and used by the 'Water Resources in the South East' stakeholder group to select which of the 316 available supply schemes (including imports) and 511 demand management options (considering 272 interdependencies) are to be activated to serve the inhabitants of South East of England. Selected schemes are scheduled and sized over a 25 year planning horizon. The model shows demand management options can play a significant role in the region's water supply and should be considered alongside new supplies and regional transfers.
\end{abstract}

\footnotetext{
S. Padula $\cdot$ J. J. Harou $(\bowtie)$

Department of Civil, Environmental and Geomatic Engineering, University College London, Chadwick Building, Gower Street, London WC1E 6BT, UK

e-mail: j.harou@ucl.ac.uk

L. G. Papageorgiou

Department of Chemical Engineering, University College London, Roberts Building, Torrington Place, London WC1E 7JE, UK

Y. Ji • M. Ahmad

CH2M HILL, Burderop Park, Swindon, Wiltshire SN4 0QD, UK

N. Hepworth

The Environment Agency, Guildborn House, Chatsworth Road, Worthing BN1 11LN, UK
} 
Considering demand management schemes reduced overall total discounted economic costs by $10 \%$ and removed two large reservoirs from the least-cost plan. This case-study optimisation model was built using a generalised data management software platform and solved using a mixed integer linear programme.

Keywords Water supply planning - Capacity expansion optimisation - Economic-engineering · Infrastructure planning $\cdot$ Demand management $\cdot$ South East England

\section{Introduction}

In many places including many cities, demand for water is growing. Given the time it takes to obtain permission, fund and build water infrastructure, water planners are often tasked to establish plans long in advance for how they plan to address the future water supply-demand balance. In England this time period is generally 25 years.

Choosing an appropriate schedule of infrastructure upgrades and investments is a classic water resource systems analysis problem and several water 'capacity expansion' models are described in the literature (Olaoghaire and Himmelblau 1974; Loucks et al. 1981; Mays 2005; Loucks and Van Beek 2006). Capacity expansion planning includes not only choosing which schemes to implement, but also their timing and capacities (sizing). A typical objective function is the minimisation of total discounted financial costs. Financial costs include 'expansion, shortage, maintenance, idle capacity and inventory' costs (Luss 1982). Expansion polices are considered over time for a defined planning horizon (typically 20 to 100 years for civil infrastructure).

These problems exhibit economies of scale: the cost per unit of capacity decreases with expansion size. Due to the strictly concave shape of the relevant cost functions there is an incentive to build large facilities now rather than a sequence of smaller ones (Revelle 1999). However if expenditures are pushed into the future their present worth value decreases. A trade-off must therefore be found between economies of scale and the cost of installing capacity before it is needed (Manne 1961, 1967).

Capacity expansion models can be deterministic (as in this paper), assuming one version of the future or stochastic, explicitly considering future uncertainty of supply and/or demand. Different optimisation algorithms have been used including mathematical programming (Labadie et al. 1986; Kim and Hopkins 1995; Barros et al. 2008; Hsu et al. 2008), dynamic programming (Bellman 1957; Dandy et al. 1984; Braga et al. 1985; Mahmoud 2006; Luo et al. 2007; Hsu et al. 2008; Chou et al. 2013) and heuristic optimisation methods (Savic and Walters 1997; Deb 2001). Linear programming is popular because of its assured convergence to a globally optimum solution but is limited to using only convex and linear objective functions, linear constraints and continuous decision variables (Mahmoud 2006). This can be overcome by using mixed integer programming (MIP) where some variables take integer values. MIP conveniently allows representing yes/no decisions at each time step (Mays 2005) and has been used by Tu et al. (2003) and Labadie (2004).

The proposed model poses the capacity expansion problem in a form easily tractable by a mathematical program by boiling the problem down to a supply-demand balance per water resource zone. Such 'water resource zones' (WRZ) aggregate interconnected supply areas where residents face the same likelihood of supply shortfalls. Four contributions to capacity expansion optimisation modelling are proposed. User-defined annual water saving profiles for demand management (water conservation) schemes are enabled. Multiple water demand scenarios are considered simultaneously to ensure the supply-demand balance is preserved across high demand conditions and that variable costs are accurately assessed. A wide range of supplementary 
constraints are formulated to consider the interdependencies between schemes (pre-requisite, mutual exclusivity, etc.). Finally, a two-step optimisation process is introduced to prevent the infeasibilities that inevitably appear in real applications. This model was developed and used for the 'Water Resources in the South East' project led by the Environment Agency of England and Wales in collaboration with Ofwat, Defra and six English water companies that serve 17.6 million people.

The paper is structured as follows: Section 2 describes the model formulation, Section 3 describes the water planning context in England and Wales and the model's application to a regional system, Section 4 presents model results. Discussion of model results and contributions are presented in section 5. Model limitations and benefits are discussed in Section 6 and followed by conclusions.

\section{Model Formulation}

\subsection{Basic Model Formulation}

We describe a minimum cost capacity expansion optimisation model formulation for large water supply systems which can be solved by off-the-shelf mixed integer linear program (MILP) solvers. The model identifies the least discounted economic cost annual schedule of capacity expansions to maintain the system's supply-demand balance over a T-year planning horizon.

The model makes two kinds of decisions: the extent of annual use of supply and demand management options (for both existing and optional schemes) and annual investment decisions on optional schemes. The model has a network structure: water demand nodes (Water Resource Zones, WRZs) are connected to supply and demand management options within their WRZ, or to other demand nodes (to represent transfers). To represent supply schemes that can be shared between more than one WRZ, 'source-junction' nodes are used to connect supply options to the demand nodes. The model is formulated as a mixed integer linear programming (MILP) optimisation problem. Appendix A lists the model nomenclature. A single objective is used: minimisation of discounted capital (CAPEX), fixed (FOPEX) and variable (VOPEX) costs (Eq. 1). One-off financial costs are also included. These incur just once over the planning period, when an option is selected.

$$
\min _{t=1}^{t \operatorname{tmax}} \frac{1}{(1+d r)^{t-1}}\left[\begin{array}{l}
\left.\sum_{i \in \operatorname{SUPPLYN}_{(i, j) \in C O N}}\left(\operatorname{afccs}_{i}+s f i x_{i}\right) \times A S_{i, t}+\left(\operatorname{carbs}_{i, t}+\operatorname{off}_{i}\right) \times F S_{i, t}+\operatorname{vopexs}_{i, t}+l f x_{i, j}\right) \times A L_{i, j, t}+\left(\operatorname{carbl}_{i, j, t}\right) \times F L_{i, j, t}+\operatorname{vopexl}_{i, j, t}
\end{array}\right]
$$

In the equation above $d r$ is the discount rate, tmax the final year of the planning period, $C O N$ is a set which defines the connections among nodes $i, j$ in the network, SUPPLYN is the set of all supply nodes (both existing sources EXDO and optional schemes OPTSOU). A discount factor equal to $1 /(1+d r)^{t}$ assumes all costs are incurred at the year-end. $a f c c s_{i}, a f c c l_{i, j}$ are respectively the sum of annualised CAPEX (capital financial, capital environmental and social costs, see Appendix B) for optional schemes (OPTSOU) and companies' proposed optional links (LFT), while $s f i x_{i}$ and $l f i x_{i, j}$ are respectively the fixed annual costs (operating, carbon, environmental and social) for optional nodes and links. vopexs $_{i, t}$ and vopexl $_{i, j, t}$ are variable costs (operating, carbon, environmental and social) incurred at nodes and links respectively. Finally $\operatorname{carbs}_{i, t}$ and $\operatorname{carbl}_{i, j, t}$ are user-defined annual profiles of capital carbon costs for optional sources and links respectively, while off $f_{i}$ are one-off costs applied to DM options. One-off costs include fixed financial, social, environmental and carbon emission related costs.

Environmental costs reflect the environmental impact that an option might have, whereas social costs are measured as a loss of consumer surplus (UKWIR 2002b). Carbon costs are 
related to the option emissions of carbon dioxide. To estimate carbon costs of the options projected emissions, water companies use the latest government guidance on the cost of carbon (Climate Change Economics and Dpt. of Energy and Climate Change 2009).

$S_{i, t}$ and $Q_{i, j, t}$ are non negative decision variables defining the extent of annual use of supply for sources and links respectively. $A S_{i, t}$ and $A L_{i, j, t}$ are binary decision variables that activate new supply options $i$ and new links $(i, j)$ when they change from 0 to 1 during any particular year. $F S_{i, t}$ and $F L_{i, j, t}$ are binary variables equal to one at the first year of activation of an optional node (OPTSOU) or optional link ( $L F T)$ respectively and equal to zero otherwise. $F S_{i, t}$ and $F L_{i, j, t}$ are defined by equations below:

$$
\begin{gathered}
F S_{i, t}=\left(A S_{i, t}-A S_{i, t-1}\right) \quad \forall i \in O P T S O U, t \in T \\
F L_{i, j, t}=\left(A L_{i, j, t}-A L_{i, j, t-1}\right) \quad \forall(i, j) \in L F T, t \in T
\end{gathered}
$$

In the equation above $T$ is the set of time periods (years). All decision variables are in volume/time except for binary variables which represent yes/no activation decisions. In this paper decision variables (binary and continuous) and set declarations are in upper case letters; parameters (input data) are in lower case.

Variable costs vopexs $_{i, t}$ and vopexl $l_{i, j, t}$ are calculated multiplying unit variable costs $\left(s_{v a r} r_{i, t}\right.$ for sources and $l v^{2} r_{i, j, t}$ for links) by the continuous usage decision variables $S_{i, t}$ and $Q_{i, j, t}$. Capital costs can be included as a custom time-series of cash outflows or using simple cash flow methods (Appendix B). All costs are in real and not nominal terms to avoid having to forecast inflation (Belli et al. 2001).

The objective function equation is subject to a 'mass balance' constraint at all nodes of the network (Eq. 4) and to capacity constraints at nodes and links (Eqs. 5 to 8):

$$
\left.S_{i, t}\right|_{i \in S U P P L Y N}-\left.s r_{i, t}\right|_{i \in E X D O}+\sum_{j:(j, i) \in C O N} Q_{j, i, t}-\sum_{j:(i, j) \in C O N} Q_{i, j, t}=\left.d i_{i, t}\right|_{i \in D E M}+\left.t h r_{i, t}\right|_{i \in D E M} \forall i \in I, t \in T
$$

$$
\begin{gathered}
\operatorname{smin}_{i, t} \times A S_{i, t} \leq S_{i, t} \leq \operatorname{smax}_{i, t} \times A S_{i, t} \quad \forall i \in O P T S O U, t \in T \\
\operatorname{smin}_{i, t} \leq S_{i, t} \leq \operatorname{smax}_{i, t} \quad \forall i \in E X D O, t \in T \\
\operatorname{lmin}_{i, j, t} \times A L_{i, j, t} \leq Q_{i, j, t} \leq \operatorname{lmax}_{i, j, t} \times A L_{i, j, t} \quad \forall(i, j) \in L F T, t \in T \\
\operatorname{lmin}_{i, j, t} \leq Q_{i, j, t} \leq \operatorname{lmax}_{i, j, t} \quad \forall(i, j) \in L E X, t \in T
\end{gathered}
$$

In the equations above DEM is the set of demand nodes (WRZs), $L E X$ is the set of all existing links. $\Sigma_{\mathrm{j}} Q_{j, i, t}$ is the sum of the flows entering node $i$ during year $t, \Sigma_{\mathrm{j}} Q_{i, j, t}$ is the sum of the flows leaving node $i$ during year $t$. $\operatorname{smin}_{i, t}, \operatorname{smax}_{i, t}$ are respectively the minimum and maximum capacities for schemes (EXDO and OPTSOU), while $\operatorname{lmin}_{i, j, t}$ and $\operatorname{lmax}_{i, j, t}$ are respectively the minimum and maximum capacities for links. Binary variables $A S_{i, t}, A L_{i, j, t}$ are applied only to optional sources and links. 
In Eq. $4 s r_{i, t}$ is the outage while $d i_{i, t}$ and $t h r_{i, t}$ are respectively the distribution input (DI) and target headroom (THR). Terms $d i_{i, t}$ and $t h r_{i, t}$ are applied at WRZ level. Outage is defined as a temporary short-term loss in DO (EA et al. 2012a) while the DI is the amount of treated water entering the distribution system. THR is a margin of spare resource between forecast demand and water available for use (WAFU), used to take account of uncertainty around supply and demand estimates (UKWIR 2002c). Process losses and reduction in the firm yield (referred to in the UK as 'deployable output' or DO) might be added in the equation above to increase the WRZ DI when either one are greater than zero. Process losses are defined (EA et al. 2012b) as the summation of both raw and treatment work losses and operational use. Reduction of deployable output may include factors such as sustainability reduction (i.e. reduction in DO required by the EA to meet statutory and/or environmental requirements) and impact of climate change (EA et al. 2012a). Sustainability reductions can be either a fixed value or a proportion of annual use.

\subsection{Multiple Demand Scenario Formulation}

Supplies must meet demand in relatively infrequent periods of high demand when costs are typically higher. This implies the above model will over-estimate costs under normal conditions. To prevent this we introduce multiple simultaneous water demand scenarios in a single model run. For example four demand scenarios (identified by set SCEN) are considered in our application: dry year annual average, dry year critical period, minimum deployable output and normal year annual average (see section 3.2). Supplies must meet the most stringent scenario but variable costs are considered and weighted according to how frequently each demand 'scenario' is expected. Solving $n$ demand scenarios requires $n$ sets of continuous decision variables (in place of one set for $S_{i, t}$ and $Q_{i, j, t}$ ) to describe how much each scheme (supply, demand management or transfer) is used annually under each scenario.

\subsubsection{Mass Balance and Capacity Constraints Under Multiple Water Demand Scenarios}

We introduce two sets of mass balance equations: the first (Eq. 9) to make sure that the selected infrastructure is able to meet the most stringent scenario (demand is equal to DI plus THR), the second (Eq. 10) to evaluate variable costs based on schemes actual utilisation rather than as if peak demands were maintained all year long (THR is set equal to zero). Each mass balance equation has a different set of annual use variables $\left(S_{i, t, s c e n}, Q_{i, j, t, s c e n}\right.$ in Eq. 9 and Sut $_{i, t, s c e n}$, Qut $_{i, j, t, s c e n}$ in Eq. 10). Setting THR to zero means that the required annual use variables $\left(\right.$ Qut $\left._{i, j, t, s c e n}, S u t_{i, t, s c e n}\right)$ will be lower thus incurring less variable costs (VOPEX). This ensures estimated VOPEX will reflect how much schemes are likely to be used over the 25 year period. This second set of use variables $\left(S u t_{i, t, s c e n}\right.$ and Qut $\left._{i, j, t, s c e n}\right)$ is the one that appears in the weighted VOPEX terms included in the objective function equation.

$$
\begin{aligned}
& \left.S_{i, t, s c e n}\right|_{i \in S U P P L Y N}-\left.s r_{i, t, s c e n}\right|_{i \in E X D O}+\sum_{j:(j, i) \in C O N} Q_{j, i, t, s c e n}-\sum_{j:(i, j) \in C O N} Q_{i, j, t, s c e n} \quad \forall i \in I, t \in T, s c e n \in S C E N \\
& =\left.d i_{i, t, s c e n}\right|_{i \in D E M}+\left.t h r_{i, t, s c e n}\right|_{i \in D E M}
\end{aligned}
$$

$$
\begin{aligned}
& \left.\operatorname{Sut}_{i, t, s c e n}\right|_{i \in S U P P L Y N}-\left.s r_{i, t, s c e n}\right|_{i \in E X D O}+\sum_{j:(j, i) \in C O N} Q u t_{j, i, t, s c e n} \\
& -\sum_{j:(i, j) \in C O N} Q u t_{i, j, t, s c e n}=\left.d i_{i, t, s c e n}\right|_{i \in D E M}+\left.t h r_{i, t, s c e n}\right|_{i \in D E M}
\end{aligned}
$$


Equations above are applied to each node of the network (supply nodes, junctions, demand nodes and supply junctions) and also apply to multiple demand scenarios scen and each year $t$ of the planning horizon. SCEN is the set of all demand scenarios.

Annual use variables $Q_{i, j, t, s c e n}, S_{i, t, s c e n}, Q u t_{i, j, t, s c e n}$ and $S u t_{i, t, s c e n}$ also appear in capacity constraints Eqs. 5 to 8 (in place of variables $S_{i, t}$ and $Q_{i, j, t}$ ) where the minimum and maximum capacities $\left(\operatorname{smin}_{i, t, \text { scen }}, \operatorname{smax}_{i, t, s c e n}, \operatorname{lmin}_{i, j, t, \text { scen }}, \operatorname{lmax}_{i, j, t, \text { scen }}\right)$ are now defined over set SCEN.

\subsubsection{Objective Function}

The objective function is identical to Eq. 1 with the difference that now variable costs are weighted over four scenarios (set SCEN). We use one set of CAPEX and FOPEX costs and four sets of VOPEX costs. VOPEX costs are evaluated using $Q u t_{i, j, t, s c e n}$ and $S u t_{i, t, s c e n}$ variables. If $s c e n$ are the elements of set $S C E N$ and $t_{s c e n}$ scen is the weight for each demand scenario (e.g. in number of weeks per year), then the weighted average is expressed by Eq. 11 (for nodes) and Eq. 12 (for links):

$$
\begin{aligned}
& \operatorname{vopexs}_{i, t}=\frac{\sum_{\text {scen } \in \text { SCEN }} \text { tscen }_{\text {scen }} \times \text { svar }_{i} \times \text { Sut }_{i, t, s c e n}}{\sum_{\text {scen } \in \text { SCEN }} t_{\text {scen }} \text { scen }} \forall i \in S U P P L Y N, t \in T \\
& \operatorname{vopex}_{i, j, t}=\frac{\sum_{\text {scen } \in \text { SCEN }} \text { tscen }_{\text {scen }} \times \operatorname{lvar}_{i, j} \times \text { Qut }_{i, j, t, s c e n}}{\sum_{\text {scen } \in S C E N} \text { tscen }_{\text {scen }}} \forall(i, j) \in L I N K S, t \in T
\end{aligned}
$$

where $t$ is the annual time index, LINKS is the set of existing (LEX) and optional (LFT) transfers, svar $_{i}$, lvar $_{i, j}$ and vopexs ${ }_{i, t}$, vopexl $_{i, j, t}$ are respectively the variable costs in pence $/ \mathrm{m}^{3}$ and the weighted average variable costs incurred at nodes and links. Scenario durations $\left(\right.$ tscen $\left._{\text {scen }}\right)$ are weights estimated based on expected occurrence with no dimension. Unit variable costs on existing links ( $L E X)$ can be used to encourage the model to use WRZs own existing deployable output (local sources) before importing from other WRZs.

\subsection{Interdependency Constraints}

Other constraints have been added to describe interdependences between options in the water supply network representing practical, technological, social and/or environmental policies and restrictions (see Appendix C). These include: 'mutually exclusive' constraints which apply when only one supply or link from a set of alternatives should be implemented, 'prerequisite AND' constraints that assure a link/source form group A is implemented only if all links/sources from group B have been activated, 'prerequisite OR' constraints that assure a link/source form group A is implemented only if at least one option (link or source) from a set B of prerequisite schemes has been activated, 'prerequisite with LAG TIME' constraints that allow a scheme to be activated only a certain number of years $(\eta)$ after the activation of another prerequisite scheme (node or link), 'dependency' constraints that force a node or link to be activated at the same time as another group of optional schemes are implemented. 'Capacity connectivity constraints' force the total supply (M1/d) from a group of schemes in set A to be lower than the total supply from selected schemes in set B, plus an allowance which may vary depending on the scenario (set SCEN). 
'Ratchet' constraints can be used to impose a monotonically increasing usage of schemes to avoid constructing schemes that are used only for few years or regularly used below their maximum capacity. Ratchet constraints are a good example of a policy or 'political' constraint. 'Consistent use constraints' (also referred to as 'capacity constraints', see Appendix B) are used to discourage the discontinuous use of future supply sources by forcing the binary variables of optional schemes and links to be one after their first year of activation). Finally, start date constraints limit the first use of any link or supply scheme and represent the time it takes to construct and receive benefits from the options.

\subsection{Demand Management Option Constraints}

Demand management options (set $D M$ ) have user-defined annual water saving profiles which start from their first year of activation. Capacity constraints on DM options can be implemented following to the two methods provided below: fixed start year or flexible start year.

\subsubsection{Fixed Start Year for DM Options}

In some cases it may be desirable to only allow activation of a DM option during a specific year. To ensure DM options are activated at their first available year $\left(d m \_a v l_{i}\right)$ the following equation is used:

$$
\sum_{t}\left(A S_{i, t}-A S_{i, t-1}\right) \times t \leq d m_{-} a v l_{i}-\text { first }_{-} y r+1 \quad \forall i \in D M, t \in T
$$

where first $y r$ is the first year of the planning horizon, $d m_{-} a v l_{i}$ is the first year of availability of each DM option.

Capacity constraints for DM options whose allowed year of activation is fixed are set to a user-defined profile using the following equations:

$$
S_{i, t, s c e n}=\operatorname{sav}_{i, \theta, s c e n} \times A S_{i, t} \quad \forall i \in D M, t \in T, \theta \boldsymbol{э}^{\prime}\left[\theta+d m_{-} a v l_{i}-f i r s t_{-} y r=t\right]
$$

where $\operatorname{sav}_{i, \theta, \text { scen }}$ is a table of input data containing the saving profile for each DM option. $\Theta$ is a generic set containing as many elements $\theta$ as the number of years included in the planning horizon.

\subsubsection{Flexible First Year of Availability}

When the first year of DM option activation is a decision to be optimised, then DM capacity constraints are written as:

$$
S_{i, t, s c e n}=\sum_{\theta=1}^{\theta \max } \operatorname{sav}_{i, \theta, s c e n} \times F S_{i, t-\theta} \quad \forall i \in D M, t \in T, \text { scen } \in S C E N
$$

$\theta \max$ is the last element of set $\Theta$. Equation 15 ensures annual 'supply' from DM options is accounted from their first year of activation.

Unlike supply schemes that can be used in any given year less than maximum capacity (Eqs. 5 to 8), DM scheme contributions are fixed to the scheme's forecasted ability to reduce demand ( $s a v_{i, \theta, s c e n}$, see Eqs. 14 and 15). This means that, for selected DM options, the extent of annual use variable $S_{i, t, s c e n}$ has to assume the same value to the one as variable Sut $_{i, t, s c e n}$. 
This is ensured through the following constraint:

$$
S_{i, t, s c e n}=S_{i, t, s c e n} \quad \forall i \in D M, t \in T, \text { scen } \in S C E N
$$

Equation 13 ensures that DM options are not activated before their first available year $\left(d m \_a v a l_{\mathrm{i}}\right)$, while equation 14 forces any savings (variable $\mathrm{S}_{i, t, s c e n}$ ) before year $d m \_a v a l_{\mathrm{i}}$ tobe zero. This prevents DM schemes from activating before they are available.

\subsection{Dealing with Model Infeasibilities}

Mathematical infeasibilities can arise when the sum of all available supply and DM schemes cannot meet the demand of one or more WRZs in one or more years. Two strategies are available to deal with network infeasibilities: 1) infeasibility flows, where strongly penalised flows can be injected at WRZ demand nodes during any year to allow feasibility, and 2) demand reductions, where demands are reduced just enough to ensure all WRZ supply-demand balances are feasible in each year. Although method 1 is frequently adopted in network optimisation, defining high unit ('penalty') costs for the infeasibility flows can make the model less sensitive to the real scheme costs and lead to sub-optimal results. We therefore adopted method 2 in this project.

\subsubsection{Infeasibility Flow Procedure}

If this method is implemented the mass balance constraint previously defined by Eq. 9 is modified into Eq. 17. The same modifications must be applied to mass balance Eq. 10 .

$$
\begin{aligned}
& \text { INFEAS_FLOW }\left.W_{i, t, s c e n}\right|_{i \in D E M}+\left.S_{i, t, \text { scen }}\right|_{i \in S U P P L Y N} \\
& -\left.s r_{i, t, \text { scen }}\right|_{i \in E X D O}+\sum_{j:(j, i) \in C O N} Q_{j, i, t, s c e n}-\sum_{j:(i, j) \in C O N} Q_{i, j, t, s c e n} \quad \forall i \in I, t \in T, \text { scen } \in S C E N \\
& =\left.\quad d i_{i, t, s c e n}\right|_{i \in D E M}+\left.t h r_{i, t, s c e n}\right|_{i \in D E M}
\end{aligned}
$$

In the equation above INFEAS_FLOW $W_{i, t, s c e n}$ is a continuous positive variable representing flows (fictitious supply in volume per year) that can be injected at the WRZ level (set $D E M$ ) during each year $t$ and scenario scen. These flows have high ('penalty') costs to ensure they are used only in case the network is infeasible (the existing and proposed supply-side and demand-side options are insufficient to meet future demands).

The objective function Eq. 1 now becomes:

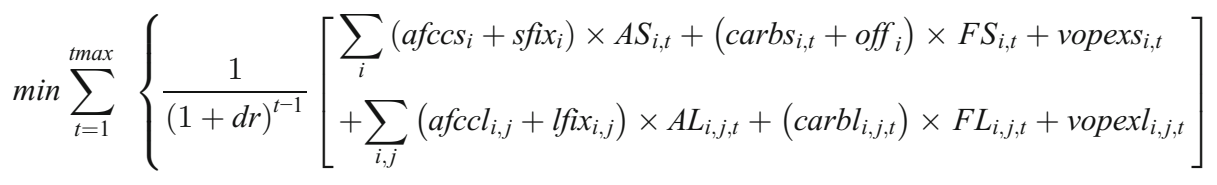

$$
\begin{aligned}
& \left.+\left[\text { penalty_cost } \times \sum_{s c e n \in S C E N} \sum_{i \in D E M} I N F E A S_{-} F L O W_{i, t, s c e n}\right]\right\}
\end{aligned}
$$

A limitation of this method is the definition of the unit cost penalty_cost. If this is too low, infeasible flows may be chosen over available optional schemes (OPTSOU), if it is too high the objective function value (Eq. 18) may become so large that the model becomes less sensitive to the real scheme costs and therefore produces suboptimal results. This issue led us to develop and use the procedure described below. 


\subsubsection{Demand Reduction Procedure}

The demand reduction procedure deals with infeasibilities in the WRSE network through a 2-step process: 1. reduce demands in WRZs in years with an infeasible balance just enough to make those balances feasible, 2 . run the feasible model with reduced demands.

Step 1: Solve the following problem:

$$
\max \sum_{\text {scen } \in S C E N} \sum_{i \in D E M} \sum_{t \in T} \alpha_{i, t, s c e n}
$$

Subject to all constraint equations listed in the previous sections (and eventually also in Appendix C) with the additional condition that $0 \leq \alpha_{i, t, s c e n} \leq 1$. Mass balance Eqs. 9 and 10 are now written as:

$$
\begin{aligned}
& \left.S_{i, t, s c e n}\right|_{i \in S U P P L Y N}-\left.s r_{i, t, s c e n}\right|_{i \in E X D O} \\
& +\sum_{j:(j, i) \in C O N} Q_{j, i, t, s c e n}-\sum_{j:(i, j) \in C O N} Q_{i, j, t, s c e n} \quad \forall i \in I, t \in T, s c e n \in S C E N \\
& =\left.\alpha_{i, t, s c e n}\right|_{i \in D E M} \times\left(\left.d i_{i, t, s c e n}\right|_{i \in D E M}+\left.t h r_{i, t, s c e n}\right|_{i \in D E M}\right) \\
& \left.S_{i, t, s c e n}\right|_{i \in S U P P L Y N}-\left.s r_{i, t, s c e n}\right|_{i \in E X D O}+\sum_{j:(j, i) \in C O N} Q_{j, i, t, s c e n} \\
& -\sum_{j:(i, j) \in C O N} Q_{i, j, t, s c e n}=\left.\alpha_{i, t, s c e n}\right|_{i \in D E M} \times\left. d i_{i, t, s c e n}\right|_{i \in D E M} \quad \forall i \in I, t \in T, s c e n \in S C E N
\end{aligned}
$$

Step 2: Fix $\alpha_{i, t, s c e n}$ values obtained from step 1 and solve the model using Eq. 1 as objective function, Eqs. 20 and 21 for mass balances, all other constraints described in previous paragraphs and constraints in Appendix $\mathrm{C}$ if required. In the equations above, $\alpha_{i, t, s c e n}$ is a continuous positive variable defined for all demand scenarios.

\section{Application: Planning South East England's Water Supply}

\subsection{Water Planning in England and Wales}

Since 1989 England is served by 22 privatised water companies (utilities) which operate as regulated natural monopolies. Their abstraction from the environment is regulated by the Environment Agency (EA) and their consumer prices and investments in water supply solutions are regulated by Ofwat (the water services regulation authority). Water companies must demonstrate to regulators their plans to meet future demand are best value and maintain environmental standards or explain and justify other considerations that move away from these criteria. Plans must follow regulatory guidance (EA et al. 2012a, b) and typically use the 'Economics of Balancing Supply and Demand' (EBSD) framework to generate socially efficient least economic cost water resource supply plans (UKWIR 2002a, b).

The water companies operating in South East England have a history of working together as the Water Resources in the South East (WRSE) Group (von Lany et al. 2013); a Group which 
includes the Environment Agency, Ofwat, the Consumer Council for Water and Defra. SouthEast England is the driest part of the UK with the largest and fastest growing population.

The group's aim is to explore new opportunities for water companies to share resources (new bulk supply agreements) and over the past few years has used capacity expansion models following the EBSD framework (EA 2005, 2010; Critchley and Marshallsay 2013). The idea behind the WRSE model is to enable water companies to jointly plan a regional water supply solution that aligns with the mix and schedule of least-cost schemes identified by the regional optimisation modelling (EA 2010). Regional modelling carried out in 1990 led to the implementation, by 2005 , of four new bulk transfers between companies. In 2010 the WRSE group identified that a savings of $£$ M 501 could be possible in the South East Region by 2035 if more sharing of existing and new resources was adopted by the six companies, rather than each company adopting its own preferred plan (EA 2010). The WRSE group recently carried out a new phase of regional modelling using the model formulation published here to identify options (new supplies, demand management and bulk transfers) to be included in the next water companies' WRMPs due for regulatory approval by year 2014 (Critchley and Marshallsay 2013).

The EBSD planning framework outlined below provides the structure within which the proposed model formulation operates. The water supply planning process in England and Wales considers a 25 to 30 year planning period and uses a Water Resource Zone (WRZ) spatial scale, i.e., interconnected water supply zones with equal likelihood of suffering supply shortfalls (UKWIR 2002b). Future demands are estimated on an annual basis.

The firm yield ('deployable output' or DO) of existing and potential future sources of supply are evaluated using detailed water resource simulation models that consider hydrology, system operating rules, minimum environmental flows and other relevant hydrological, engineering, and institutional factors. Due to the uncertainty of current and future supply and demand forecasts, the EBSD method uses a safety factor called 'headroom' which aggregates all sources of supply-demand uncertainty into an annual estimate (UKWIR 2002c). Headroom is the difference between water available for use (WAFU) and estimated demand. Companies set 'target headroom' which they estimate to allow themselves to guarantee service reliability levels to consumers ('levels of service').

Analysis of annual supply and demand over the planning period identifies supplydemand imbalances (see Fig. 1) which water company planners must rectify in their plans. To do this they 1) identify all feasible options, 2) determine their costs (or benefits) which split into capital (including initial costs, maintenance and replacement), operating (fixed and variable), environmental and social (fixed and variable) and carbon emission costs (fixed and variable) (EA et al. 2012a), then 3) find the least-cost programme (timing, capacity, choice of schemes). Note that for practical reasons companies are asked to cost and size discrete schemes rather than use continuous cost curves. The model proposed in this publication accomplishes step 3. Inclusion of carbon, social and environmental economic costs means the model can be considered an economic-engineering tool (Lund et al. 2006) rather than an engineering (financial cost minimising) model.

\subsection{Case-Study Water Resource System}

The proposed capacity expansion optimisation model is applied to a regional system composed of 34 WRZs, managed by the 6 water companies in South East England that serve a 17.6 million population (Critchley and Marshallsay 2013). Input data for the model (demands by WRZ, all costs, capacities of existing and optional schemes, outage, process 


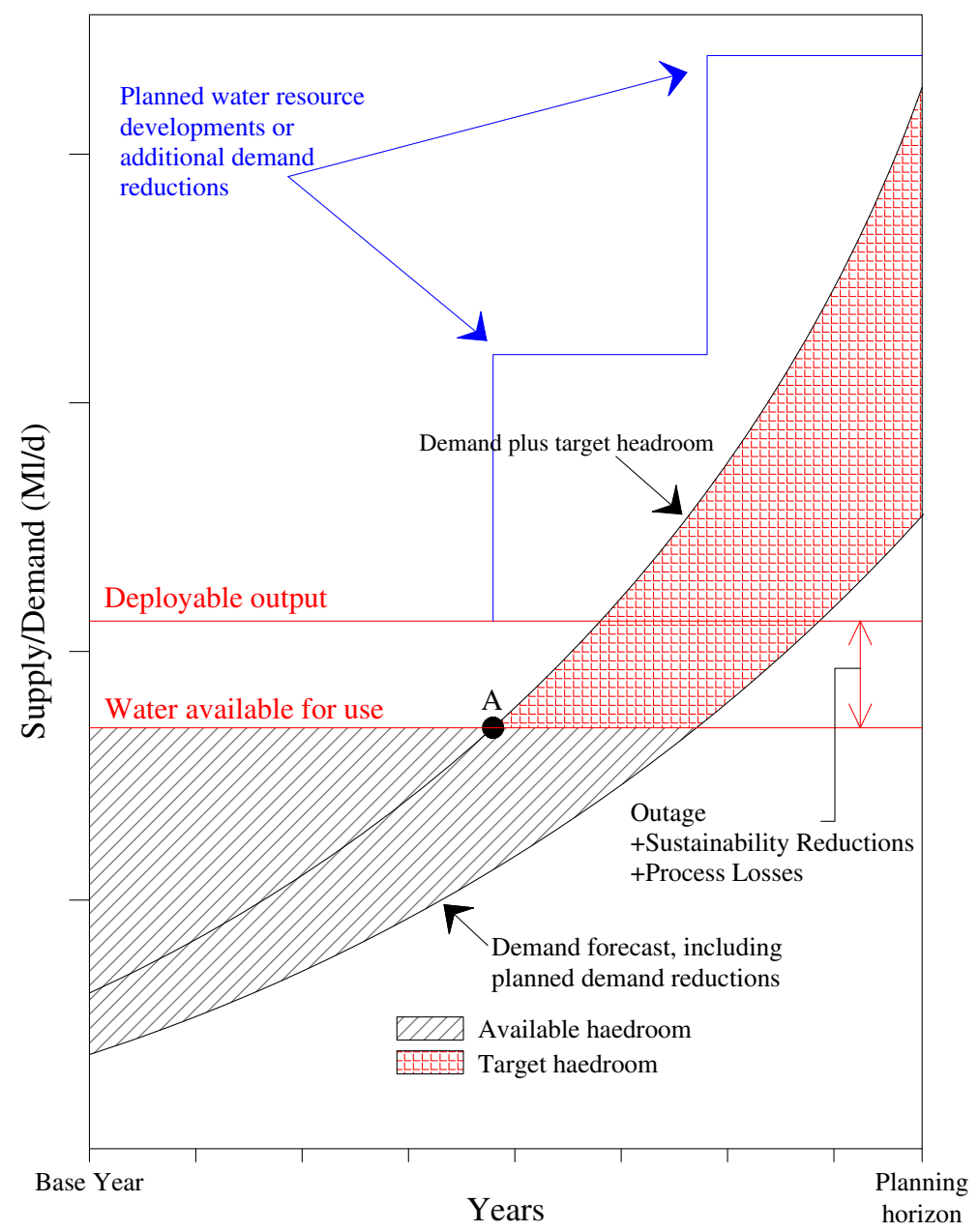

Fig. 1 The supply demand balance as considered in England and Wales water planning [adapted from UKWIR 2002b]. Demand plus target headroom must be greater than water available for use (yield of 'DO', minus losses, outage and sustainability reductions)

losses, sustainability reductions and climate change allowances) are provided by the water companies for each WRZ.

Process losses, reductions of deployable output, target headroom and water demand are aggregated at WRZ level. Four demand scenarios are here included: dry year annual average (DYAA), normal year annual average (NYAA), dry year critical period (DYCP) and minimum deployable output (MDO) period. The DYCP scenario has been included only if it drives the need to implement new supply and DM options (EA et al. 2012b). Dry years (DY) are periods of low rainfall without demand restrictions. DYAA is the dry year average annual demand while DYCP is the dry year demand over a period of peak demand (normally defined as a week, see Fig. 2). The MDO period applies when supplies are expected to be at their minimum (see Fig. 2). This normally occurs in autumn when river flows and/or ground water levels are at their lowest and sources operate close to their minimum deployable output (DO). 


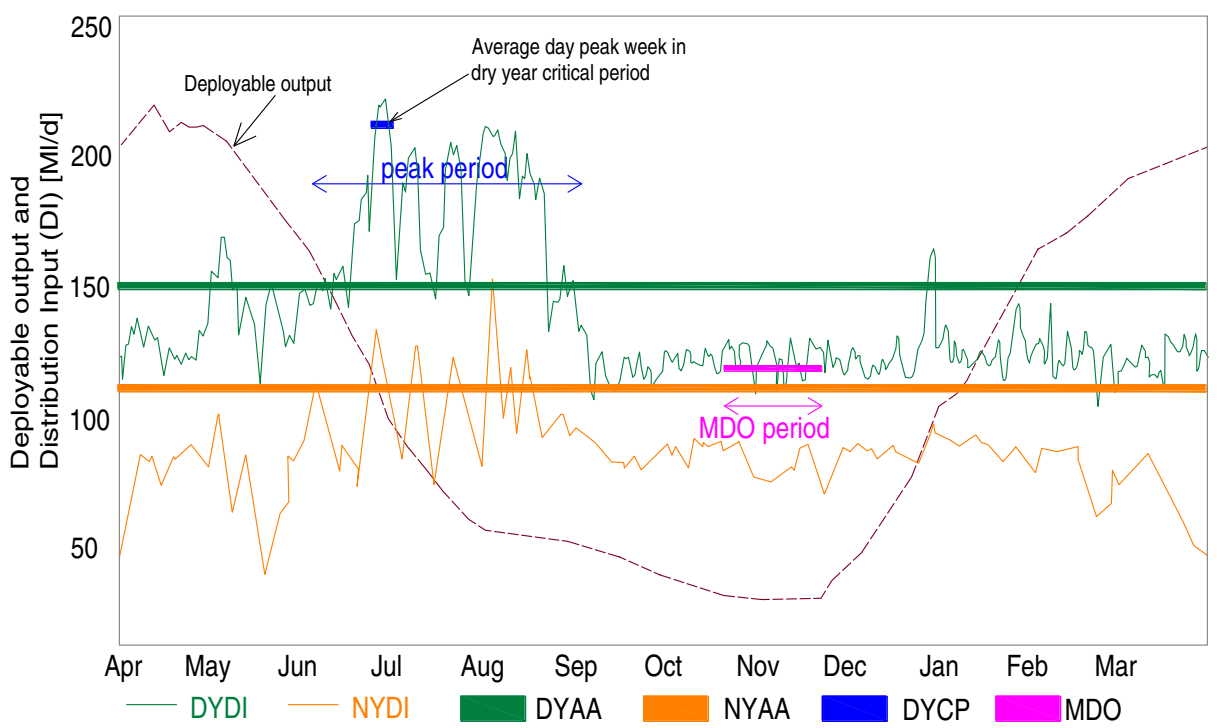

Fig. 2 Definition of annual demand scenarios (NYAA, DYCP, MDO and DYAA) [adapted from South East Water, 2009]. DYAA is the average demand over a dry year with no demand restrictions, DYCP is the average demand over a 'peak demand period' (typically a week) during a dry year with no restrictions, MDO is the average demand over the period when supplies available (deployable output) are expected to be at their minimum. DYDI is the dry year daily demand as quantified by distribution input (DI), i.e. what companies input to their networks. NYAA is the average demand over a year with normal weather patterns; NYDI is an example of normal year daily demand

Links between WRZs are either existing or optional. Optional links represent new transfers between WRZs or the prolonging of existing agreements. When optional transfers start from WRZs or areas not in the modelled network they are represented as new supply nodes (TR nodes).

Besides water demand nodes (representing WRZs) and junctions, network nodes are either existing or optional supply sources. Optional nodes are divided into supply-side schemes and demand management (DM) schemes. DM schemes include water efficiency (WEFF), leakage (LEAK) and metering (MET).

Supply-side schemes represented as nodes include reservoirs (RES), groundwater utilization schemes (GW), surface water abstraction (SW), effluent reuse schemes (ER), desalination (DESAL), water treatment works (WTW), aquifer storage and recovery schemes (ASR), and other options (Other) as conjunctive use schemes, network constraints removal or network improvements.

Some major supply schemes have several discrete capacities and cost values included as separate mutually exclusive nodes. For example, reservoir options in the Upper Thames area are proposed in different sizes which can be build in one phase or in two separate phases (e.g. $50 \mathrm{Mm}^{3}$ in phase $1+50 \mathrm{Mm}^{3}$ in phase 2). In some cases the phase 2 option can only be implemented a pre-defined number of years after the phase 1 option is selected (pre-requisite constraint with lag time).

DM options have water company defined annual water saving profiles which start from their first year of activation. Leakage reduction (LEAK) options include pressure management with new pressure release valves, district metering area data analysis for targeted repairs or network improvements, and reconfiguration as well as other strategies such as new detection technologies. Pro-actively fixing leaks before they are reported is referred to as 
active leakage control (ALC). ALC options have diminishing returns as their level of implementation increases. To gauge the extent to which ALC should be implemented, companies consider 'tranches' (bundles) of implementation. Each tranche is represented in the model with different prerequisite options (e.g. 'tranch2' can only be implemented after 'tranchl'). Successive tranches have diminishing returns: WAFU is the same but capital and operating costs increase.

Metering options (MET) include 'change of occupier' instalments (COM), metering on left over domestic or commercial properties (e.g. difficult to fit), targeted compulsory metering, community integrated metering (new meters and upgrade of existing ones), metering of all household within a stressed areas (MET_STR) and achievement of maximum meter penetration by a pre-defined year. MET options also include seasonal tariff and rising block tariff. Tariff is exclusive to COM and MET_STR schemes.

Water efficiency measures (WEFF) include a range of different measures: household and commercial water audit, supply or retrofit of efficient devices (water butts, low flow taps, low use washing machine), rainwater harvesting and grey water reuse schemes.

The proposed model is applied to two different networks: Case 1 and Case 2. In Case 1 only supply-side options are included whereas Case 2 includes both new supplies and DM schemes (water conservation). Both models use the same least economic cost objective function, demand reduction feasibility assurance scheme (see paragraph 2.5.2), mass balance constraints (Eqs. 20 and 21 ) and scheme interdependence constraints (see Appendix C). The 272 interdependence constraints used in the model (in both cases) include mutual exclusivity (103 constraints), pre-requisites ('and' 91 of which 1 with 'lag time', 'or' 4 - see Appendix C for definitions of the constraint subtypes), mutual dependency (68 constraints) and 6 'capacity connectivity' constraints.

\section{Model Results}

We solve the model over a 25 year planning period (2015-2039) with a $4.5 \%$ discount rate (Ofwat 2009) for Case 1 (only supply-side options) and Case 2 (supply and DM options) over the four demand scenarios (DYAA, DYCP, MDO and NYAA). The MILP model is implemented in GAMS (Brooke et al. 2010) and solved using the CPLEX 12 solver. Table 1 gives model dimensions for Cases 1 and 2 .

Figure 3 shows the optional schemes and transfers activated by the model over the 25 years for Case 1 and Case 2 respectively.

The model also provides the optimal annual use levels of supply options and transfers (demand management schemes are either on/off) for each demand scenario. Least cost usages (Ml/d) of selected schemes are shown in Fig. 4 for Cases 1 and 2 for the DYCP scenario.

The Case 1 solution is dominated by large investments in reservoir schemes. Two big reservoirs (RES18 and RES36) are activated. These provide a total supply of $152.4 \mathrm{Ml} / \mathrm{s}$ with a total discounted capital cost of £M 124 equivalent to the $85.5 \%$ of total capital investment on RES options (see Table 3).

The Case 2 solution is dominated by smaller options including DM options. DM options activated include 103 LEAK, $138 \mathrm{WEFF}$ and 3 MET schemes. Reservoirs RES18 and RES36 are

Table 1 Model statistics for Case 1 and Case 2 runs

\begin{tabular}{lll}
\hline & Case 1 & Case 2 \\
\hline Total number of variables & 487,551 & 623,376 \\
Binary variables & 26,366 & 59,150 \\
\hline
\end{tabular}




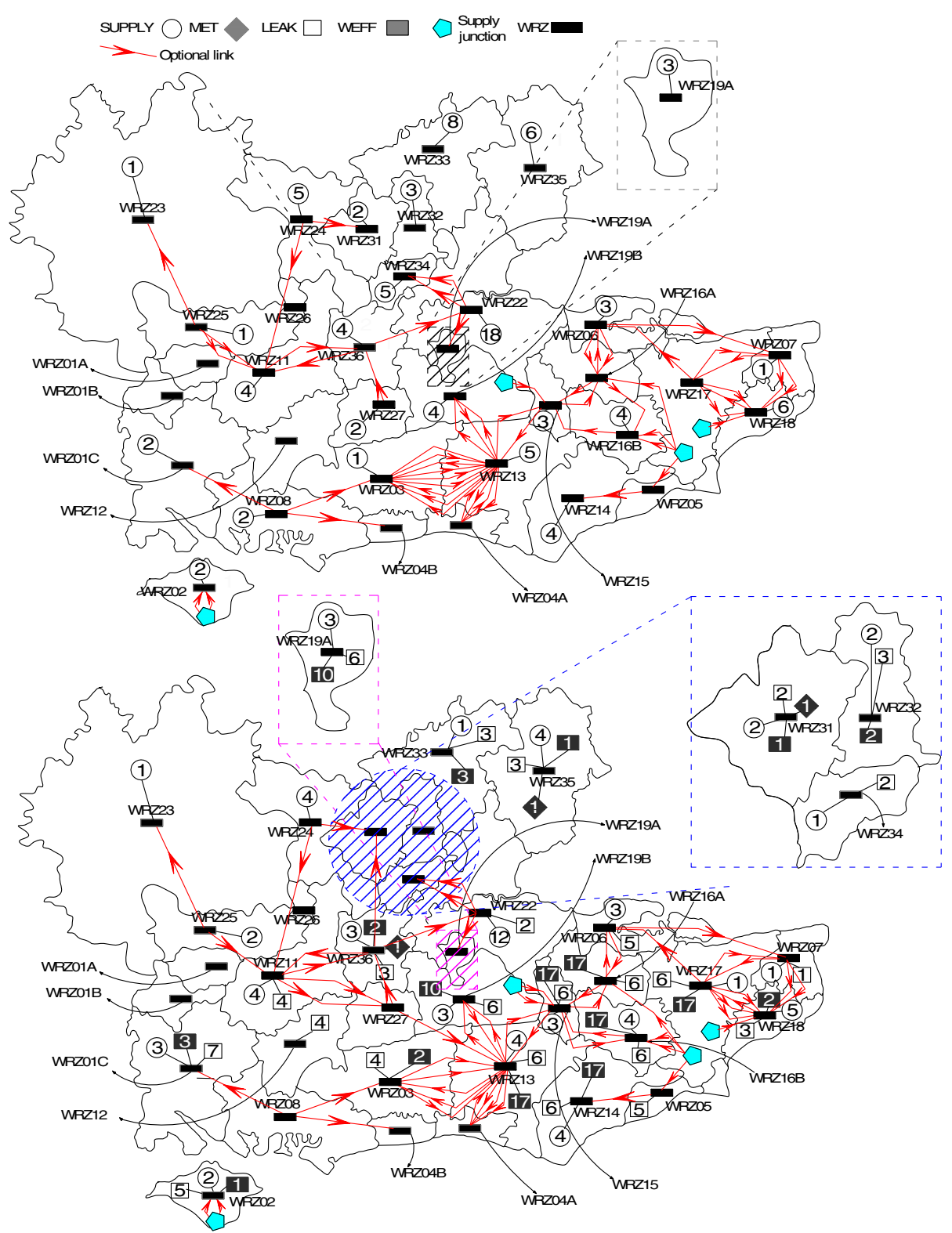

Fig. 3 Selected optional schemes and transfers for Case 1 (top panel - new supplies only) and Case 2 (bottom panel - supply and demand management schemes considered jointly). Dashed boxes contain zoomed out information. Numbers inside the various shapes represent the total number of options activated in each WRZ for a specific option type. Options types include: supply-side schemes (SUPPLY), metering (MET), leakage reduction (LEAK) and water efficiency (WEFF) measures

no longer selected leading to a significant cost reductions (capital costs on RES options are reduced from M£ 145 to $\mathrm{M} £ 10$, see Table 3). Weighted variable costs (WEIGH_VOPEX) are also reduced by $33 \%$ (i.e. from M£ 134 in Case 1 to M£ 90 in Case 2, see Table 2). This is due to 


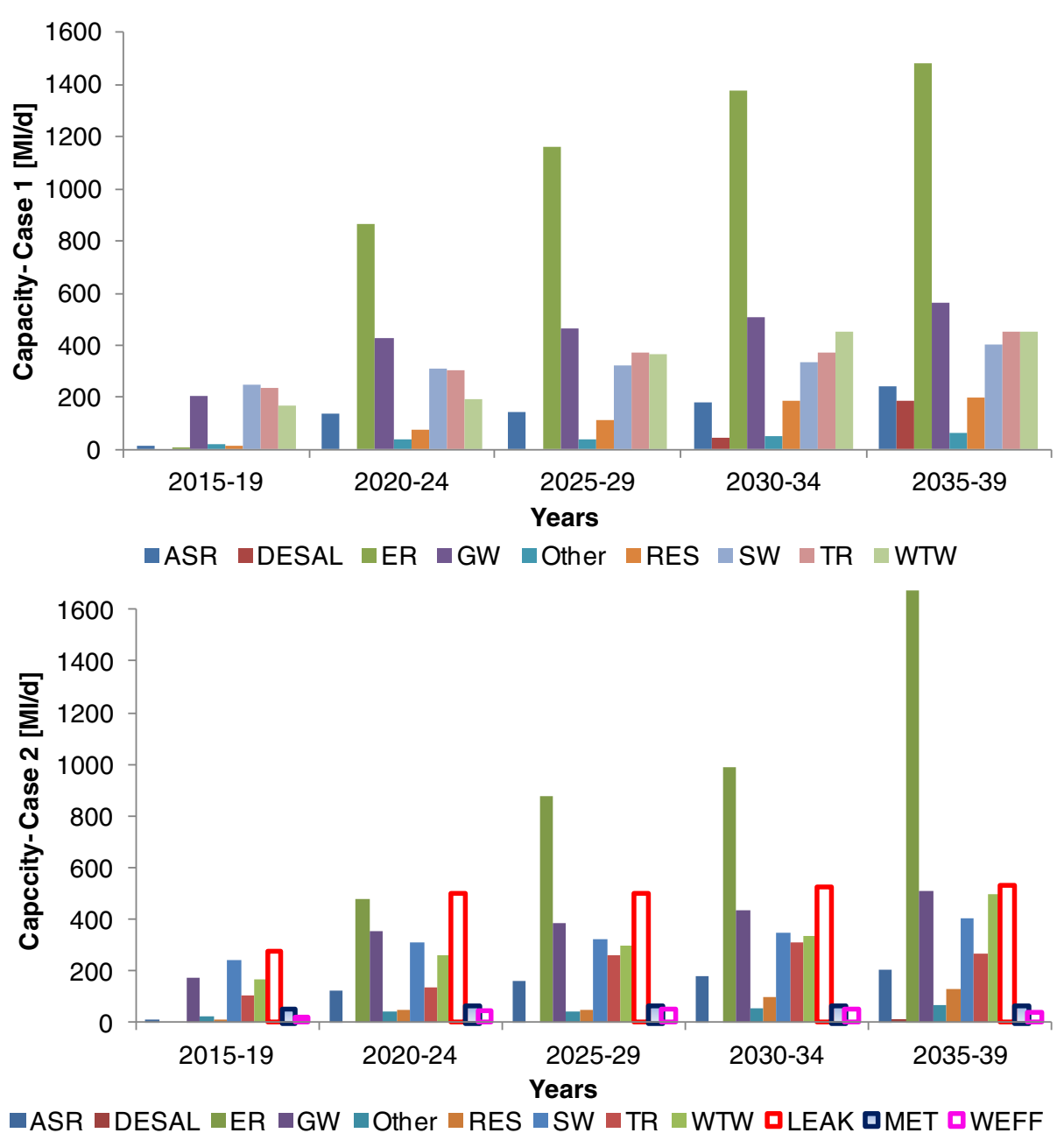

Fig. 4 Least-cost quantity of supply-side schemes and imports from external areas (TR) under the DYCP scenario for Case 1 (upper figure) and Case 2 (lower figure)

a lower use/activation of supply-side schemes compared to Case 1 (e.g. WEIGH_VOPEX drops by $21 \%$ for ER schemes and by $83 \%$ for ASR options, see Table 3) and to negative carbon costs. Negative carbon costs represent savings in greenhouse gas emissions due to the capability of DM options to reduce water demands and the subsequent need for additional supply-side schemes.

Table 4 gives a summary of the total optimal capacity provided by selected options for Case 1 and Case 2. LEAK and supply-side options contribute most significantly to the supply-demand balance; LEAK options provide $21 \%$ of total supply, while supply side options utilisation varies from a minimum of $64 \%$ under the NYAA scenario to a maximum of $79 \%$ under the DYCP scenario (see Table 4 ).

Total deficits in Case 2 are lower than Case 1 (see Table 5) because the Case 1 network has fewer options to meet projected demands (it does not include DM schemes) and available schemes are often limited by 'starting date' constraints. 
Table 2 Total discounted costs over 25-year time horizon for the Case 1 and Case 2 networks for transfers, supply options and different DM types. 'Links' refer to both TR nodes and LFT bulk transfers among WRZs. Columns may not add up due to rounding

\begin{tabular}{|c|c|c|c|c|c|c|c|c|}
\hline & \multicolumn{4}{|l|}{ Case 1} & \multicolumn{4}{|l|}{ Case 2} \\
\hline & $\begin{array}{l}\text { CAPEX } \\
{[\mathrm{M} £]}\end{array}$ & $\begin{array}{l}\text { FOPEX } \\
{[\mathrm{M} £]}\end{array}$ & $\begin{array}{l}\text { Weighted } \\
\text { VOPEX [M£] }\end{array}$ & $\begin{array}{l}\text { ONE-OFF } \\
\text { costs }\end{array}$ & $\begin{array}{l}\text { CAPEX } \\
{[\mathrm{M} £]}\end{array}$ & $\begin{array}{l}\text { FOPEX } \\
{[\mathrm{M} £]}\end{array}$ & $\begin{array}{l}\text { Weighted } \\
\text { VOPEX [M£] }\end{array}$ & $\begin{array}{l}\text { ONE-OFF } \\
\text { costs }\end{array}$ \\
\hline Supply options & 635 & 39 & 130 & 0 & 367 & 26 & 97 & 1 \\
\hline MET & - & - & - & - & 29 & 5 & -8 & I \\
\hline LEAK & - & - & - & - & 141 & 10 & -1 & 1 \\
\hline WEFF & - & - & - & - & 0 & 0 & -1 & 82 \\
\hline Links & 165 & 42 & 4 & 0 & 131 & 34 & 4 & 1 \\
\hline TOTAL & 800 & 80 & 134 & 0 & 668 & 75 & 90 & 82 \\
\hline
\end{tabular}

Figure 5 shows the magnitude (in Ml/d) of deficits in WRZs where they occur for Case 1 (upper figure) and Case 2 (lower figure) and under the four demand scenarios (there are no deficits under the NYAA scenario).

\section{Discussion of Model Results and Contributions}

Including demand management options reduced total NPV of CAPEX by $16.5 \%$ (from $800 \mathrm{M} £$ in Case 1 to $668 \mathrm{M} £$ in Case 2, cf. Table 2), FOPEX by $6 \%$ (80 to $75 \mathrm{M}$, cf. Table 2) and VOPEX by $33 \%$ (134 1o $90 \mathrm{M}$, cf. Table 2). Total discounted costs for Case 2 decrease by $10 \%$ compared to Case 1 which is equivalent to a saving of $99 \mathrm{M}$. The application of the proposed capacity expansion model to South East England argues in favour of joint supply and demand management efforts to meet future water demands. The proposed model is effective at suggesting economically efficient capacity expansion schedules for a large system with 316 costed supply options, 511 demand management options,

Table 3 Discounted costs for activated links and supply-side options aggregated by option type for both Case 1 and Case 2 networks. Columns may not add up due to rounding

\begin{tabular}{|c|c|c|c|c|c|c|}
\hline & \multicolumn{3}{|l|}{ Case 1} & \multicolumn{3}{|l|}{ Case 2} \\
\hline & $\begin{array}{l}\text { CAPEX } \\
{[\mathrm{M}]}\end{array}$ & $\begin{array}{l}\text { FOPEX } \\
{[\mathrm{M} £]}\end{array}$ & $\begin{array}{l}\text { Weighted } \\
\text { VOPEX [M£] }\end{array}$ & $\begin{array}{l}\text { CAPEX } \\
{[\mathrm{M} £]}\end{array}$ & $\begin{array}{l}\text { FOPEX } \\
{[\mathrm{M} £]}\end{array}$ & $\begin{array}{l}\text { Weighted } \\
\text { VOPEX [M£] }\end{array}$ \\
\hline ASR & 32 & 4 & 6 & 15 & 2 & 1 \\
\hline DESAL & 28 & 3 & 0 & 1 & 0 & 0 \\
\hline ER & 248 & 16 & 104 & 182 & 9 & 82 \\
\hline GW & 131 & 11 & 12 & 97 & 7 & 9 \\
\hline Other & 2 & 0 & 0 & 2 & 0 & 0 \\
\hline RES & 145 & 3 & 4 & 10 & 2 & 1 \\
\hline SW & 12 & -1 & 1 & 13 & -6 & 1 \\
\hline WTW & 36 & 3 & 3 & 30 & 2 & 2 \\
\hline TR & 54 & 16 & 2 & 15 & 9 & 2 \\
\hline LFT & 165 & 42 & 4 & 116 & 25 & 2 \\
\hline
\end{tabular}


Table 4 Total least-cost quantity in Ml/d for activated supply-side schemes and DM measures for Case 1 and Case 2

\begin{tabular}{|c|c|c|c|c|c|c|c|c|}
\hline & \multicolumn{4}{|l|}{ Case 1} & \multicolumn{4}{|l|}{ Case 2} \\
\hline & DYAA & DYCP & MDO & NYAA & DYAA & DYCP & MDO & NYAA \\
\hline MET & I & I & I & l & 287 & 287 & 287 & 287 \\
\hline LEAK & I & I & I & l & 2365 & 2365 & 2365 & 2365 \\
\hline WEFF & I & I & I & l & 192 & 192 & 192 & 192 \\
\hline $\begin{array}{l}\text { Total Capacity in } M I / d \text { and as } \% \\
\text { of total supply for DM } \\
\text { measures }\end{array}$ & / & / & / & / & $\begin{array}{l}2844 \\
(25 \%)\end{array}$ & $\begin{array}{l}2844 \\
(21 \%)\end{array}$ & $\begin{array}{l}2844 \\
(25 \%)\end{array}$ & $\begin{array}{l}2844 \\
(36 \%)\end{array}$ \\
\hline ASR & 245 & 708 & 245 & 185 & 42 & 488 & 42 & 42 \\
\hline DESAL & 111 & 183 & 71 & l & l & 7 & / & / \\
\hline ER & 4616 & 4802 & 4621 & 4280 & 3795 & 3915 & 3853 & 3510 \\
\hline GW & 1197 & 2134 & 1252 & 907 & 1029 & 1755 & 1006 & 652 \\
\hline Other & 190 & 213 & 192 & 175 & 176 & 203 & 181 & 157 \\
\hline RES & 496 & 570 & 508 & 257 & 264 & 309 & 273 & 60 \\
\hline SW & 1120 & 1582 & 1119 & 57 & 1120 & 1579 & 1104 & 42 \\
\hline WTW & & & & & 1014 & 1486 & 955 & 137 \\
\hline TR & 1239 & 1604 & 1252 & 182 & 983 & 1164 & 1021 & 494 \\
\hline $\begin{array}{l}\text { Capacity in Ml/d and as \% of } \\
\text { total supply for supply-side } \\
\text { and TR schemes }\end{array}$ & $\begin{array}{l}10255 \\
(100 \%)\end{array}$ & $\begin{array}{l}13086 \\
(100 \%)\end{array}$ & $\begin{array}{l}10497 \\
(100 \%)\end{array}$ & $\begin{array}{l}6573 \\
(100 \%)\end{array}$ & $\begin{array}{l}4824 \\
(75 \%)\end{array}$ & $\begin{array}{l}10906 \\
(79 \%)\end{array}$ & $\begin{array}{l}8435 \\
(75 \%)\end{array}$ & $\begin{array}{l}5093 \\
(64 \%)\end{array}$ \\
\hline Total Supply & 10255 & 13086 & 10497 & 6573 & 11268 & 13750 & 11279 & 7937 \\
\hline
\end{tabular}

and 272 interdependency conditions, some quite complex stringing together several proposed schemes. Four contributions to capacity expansion modelling of large inter-connected regional water supply systems are introduced in this paper; their impact on our ability to solve the case-study problem are summarised below.

Demand management (DM) measures are considered in addition to new supply schemes. Special capacity constraints are introduced to allow user-defined annual water capacity (savings) profiles based on empirical evidence gathered by utilities. The introduction of DM options allowed finding a more cost-effective plan and, in our application, avoiding or delaying new infrastructure investments.

The model is conservative in that it ensures the annual supply-demand balance under dry period demands. Because the model considers variable costs (VOPEX) in its investment decisions, it is important that high variable costs associated with drier periods are not applied throughout the year. To address this we embed multiple simultaneous demand scenarios so that VOPEX costs (which depend on the extent to which schemes are used) can be weighted by how frequently a demand

Table 5 Total regional deficit (in $\mathrm{Ml} / \mathrm{d}$ ) and level of demand satisfaction in \% for the Case 1 and 2 networks

\begin{tabular}{|c|c|c|c|c|c|c|c|c|}
\hline & \multicolumn{4}{|l|}{ Case 1} & \multicolumn{4}{|l|}{ Case 2} \\
\hline & DYAA & DYCP & MDO & NYAA & DYAA & DYCP & MDO & NYAA \\
\hline Total deficits in $\mathrm{Ml} / \mathrm{d}$ & -133 & -235 & -85 & / & -8 & -26 & -53 & / \\
\hline Total $\%$ of demand satisfaction & 99.97 & 99.95 & 99.89 & 100 & 99.99 & 99.98 & 99.92 & 100 \\
\hline
\end{tabular}


scenario is expected to occur. The model selects a single set of schemes that meets the most stringent demand estimates whilst also considering accurate variable cost estimates.

Water supply and demand management options in real systems will tend to have many interdependencies due to the engineering, social, environmental and political realities planners face. We introduce a flexible set of constraint equations that allow modellers to consider these policies and restrictions in the capacity expansion problem (Appendix C). 272 such constraints are used in our application to South East England.

A new two-step model infeasibility prevention scheme is proposed and used in the case study. It was necessary because several water supply zones could not withstand the rigorous supply-demand balance requirements. This model feasibility management scheme was an improvement over an infeasibility flow approach which was deemed unreliable since the magnitude of feasibility flow penalties affected the schemes chosen by the optimisation model.

Finally, a generic software platform was used to separate data management from modelling (Harou et al. 2010). The software allowed easily building the custom database structure and for example generating the network connectivity matrix.

\section{Model Limitations and Benefits}

The proposed model and its application have limitations stemming from the formulation itself and its application but also from the underlying structure of the problem as formalised by the UK water sector's EBSD planning framework.

1. The problem of non-convex cost functions in capacity expansion problem is overcome by a significant compromise: fixing capacities and costs into proposed discrete schemes rather than using continuous cost functions. Given each discrete option generates a computationally expensive binary variable, inevitably too few discrete possible capacity and costs values are included, a limitation which necessarily leads to the suboptimality of suggested 'least-cost' plans. This limitation is partially mitigated by the fact that water companies and regulators prefer costing discrete schemes as they are unwilling or unable in many instances to generate continuous cost curves, which in practice for large systems are not always easy to generate reliably.

2. EBSD uses yields established under historically stressed conditions. This is accurate for hydrologically disconnected sources like desalination. For sources that are hydrologically inter-connected the yield concept is less suited; non-linear interactions are considered but only under one set of historically stressed conditions. If a future stress state is different from the one that was used to establish yields, the water available from sources (yield) could be substantially different.

3. The model and our application are deterministic, the stochastic part of the problem is dealt with external pre-processors: detailed system simulators which estimate safe yield for each source option. A stochastic EBSD ('intermediate') framework (not used in this paper) uses Monte Carlo simulation to explore the effect of uncertainty in yields and demands on the reliability of the programme of measures (schedule of interventions) identified by the optimisation model. Both the deterministic (applied here) and the intermediate framework produce solutions that meet a level of service (supply reliability) agreed by water companies and regulators. This fixed reliability requirement means the EBSD approach does not generate a reliability-cost trade-off curve. Additionally, the EBSD framework and model proposed here do not seek solutions that perform well across a broad range of future conditions or that are resilient (i.e., resume function rapidly after a failure). Neither does the 

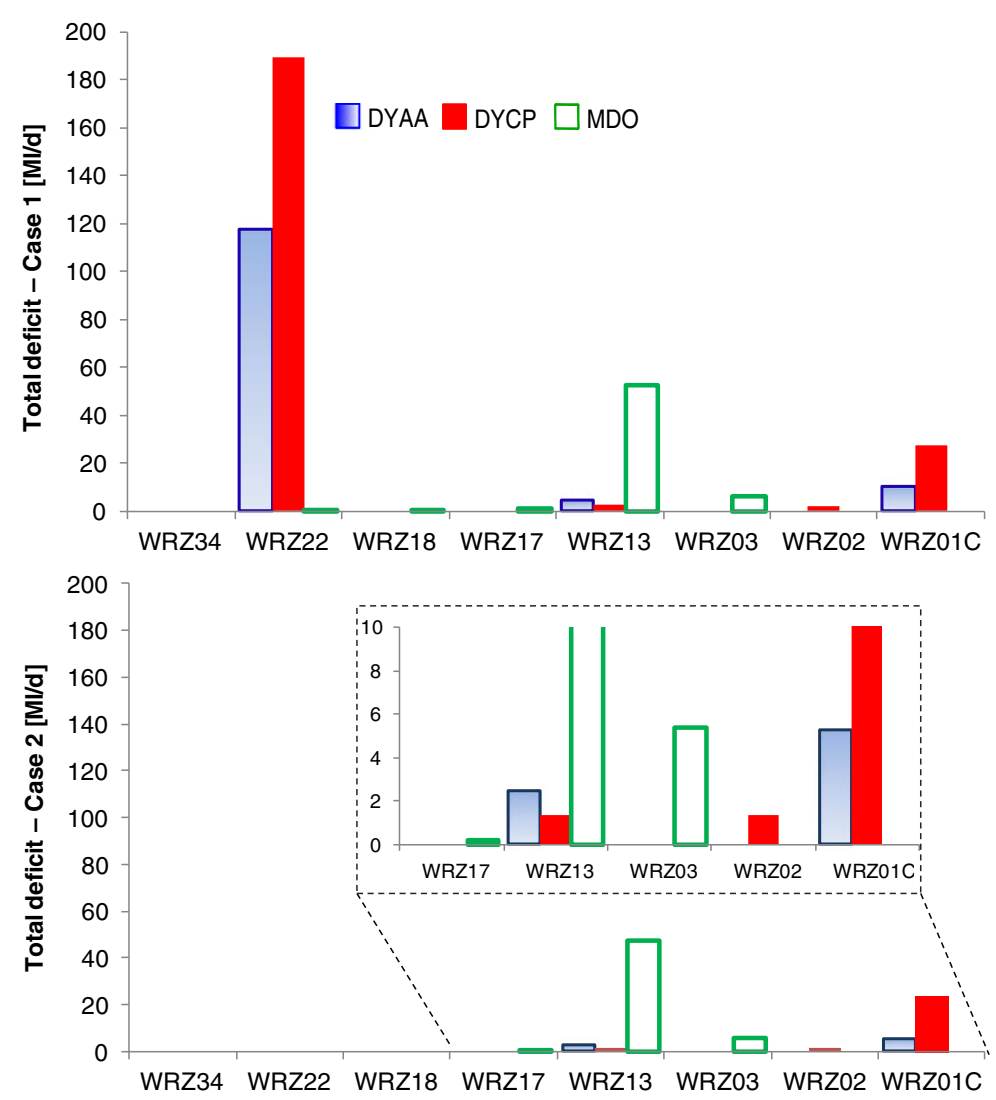

Fig. 5 Supply-demand deficits appear for some of the WRZs in the network under the DYAA, DYCP and MDO scenario. Deficits under the NYAA scenario are zero

model necessarily produce programs that are flexible and adaptable, i.e., programmes where changing course part way through the time-horizon can be cost-effectively achieved.

4. While real water supply systems are managed according to several criteria such as reliability, environmental performance, energy use, etc., the EBSD framework requires monetising all aspects of system performance and produces one 'optimal' least cost solution. System goals that cannot easily be monetised can only be represented in the model as constraints (e.g. reliability, environmental benefits, etc.). Trade-offs amongst monetary and non-monetary performance measures would be of interest to water supply planners but they are not made available using the EBSD method.

Despite several limitations, the benefit of the applied model and EBSD framework are their relative simplicity and applicability to large systems with complex interdependencies. Although water supply planning of large populous regions is complex, this framework parsimoniously boils the problem down to its most essential components to cost-effectively address the regional supply-demand planning problem for real-world systems. Not only does the model find the least-cost mix of schemes, but recommends the least cost implementation schedule to meet projected demands as well. The fact that the model formulated here is being used in a regulator- 
led effort to optimise investments for South East England with 17.6 million inhabitants is a testament to its ability to help plan real systems.

\section{Conclusions}

A least economic cost deterministic capacity expansion optimisation model was formulated. The model selects from a set of discretely costed new supply and demand management schemes to ensure the annual supply-demand balance at least economic cost over a T year time horizon. Capital (financial, environmental and social), and both fixed and variable annual carbon, operating, social and environmental costs of proposed schemes are considered. The model includes constraints designed to represent the predicted effect of conservation measures on the supply-demand balance. A series of constraints are formulated to represent complex interdependencies between proposed options which frequently manifest in real systems (there were 272 such constraints in our application). The model is conservative and assumes planners aim to satisfy peak demands with a prescribed reliability. Multiple simultaneous demand scenarios are considered in order to meet peak demands and accurately estimate variable costs. An infeasibility management scheme which reduces demand just enough to allow model feasibility (and warns the analyst) is used so that the model can still run if certain water supply zones are not able to satisfy intended reliability requirements.

The model is applied to a regional system (the whole of South East England) composed of six water utilities serving 17.6 million people. The model was run twice: initially only new transfers and supply-side schemes are considered, next demand management options are added into the dynamic portfolio optimisation problem. The availability of water conservation schemes in the planning problem reduced the total discounted economic costs by $10 \%$ over the 25 -year planning horizon. Demand management options are implemented in place of some of the most capital intensive proposed supply schemes such as two reservoirs which had high capital costs. The paper discusses limitations of the applied model and the UK water sector planning approach which led to it.

Acknowledgments The authors thank the UCL Faculty of Engineering Sciences for funding S. Padula. Model development was also partially funded by the Environment Agency of England and Wales. The authors thank Fida Choudhury, Sandy Elsworth, Meyrick Gough, Luke Lovell, Bill Baker, Andrew Ball, Peter Von Lany, and WRSE group members for contributions which improved the model. Víctor Virós Usandizaga contributed to an earlier version of the model. Two anonymous reviewers and the A.E. provided comments that strongly improved the paper. All errors and omissions are the sole responsibility of the authors.

Open Access This article is distributed under the terms of the Creative Commons Attribution License which permits any use, distribution, and reproduction in any medium, provided the original author(s) and the source are credited.

\section{Appendix A. Nomenclature}

\section{Indices of Sets}

$i, j \quad$ nodes (source, junction, demand).

$t$ time periods (years)

$\theta \quad$ generic time index

scen demand scenarios 


\section{Sets}

$I$

$T$

$\Theta$

$S C E N$

EXDO

OPTSOU

DM set of new demand management schemes

SUPPLYN set of all existing and optional supply schemes (i.e. includes sets EXDO and OPTSOU)

DEM set of demand nodes

LEX set of existing links

LFT set of new links/transfers

LINKS set of all existing and optional links (i.e. includes sets lex and lft)

CON set of all links (network connectivity)

\section{Parameters}

afccs $_{i}$
afccl $_{i, j}$
sfix $_{i}$
lfix $_{i, j}$
carbs $_{i, t}$
carbl $_{i, j, t}$
off $_{i}$
vopexs $_{i, t}$
vopexl $_{i, j, t}$
svar $_{i, t}$
lvar $_{i, j, t}$
sr $_{i, t, s c e n}$
di $_{i, t, s c e n}$
thr $_{i, t, s c e n}$
smin $_{i, t, s c e n} /$ smax $_{i, t, s c e n}$
lmin $_{i, j, t, s c e n} /$ lmax $_{i, j, t, s c e n}$
sav $_{i, \theta, \text { scen }}$
dm_aval $_{i}$
first_yr $_{\text {tscen }_{\text {scen }}}$
penalty_cost $_{\text {dr }}$

annualised capital costs (financial, social, environmental) for new nodes annualised capital costs (financial, social, environmental) for new links fixed annual costs (operating, social, environmental and carbon) for new nodes

fixed annual costs (operating, social, environmental and carbon) for new links

annual capital carbon costs emissions for optional sources annual capital carbon costs emissions for optional links one-off fixed financial operating costs for demand management(DM) schemes variable costs incurred at nodes variable costs incurred at links unit variable costs incurred at nodes unit variable costs incurred at links outage at each existing node exdo, during year $t$ and scenario scen distribution input applied to each demand node $i$, during year $t$ and scenario scen target headroom applied to each demand node $i$, during year $t$ and scenario scen

minimum/maximum supply from source $i$ during year $t$ and scenario scen

minimum/maximum supply from link $i, j$ during year $t$ and scenario scen saving from a demand management option $i$ over time index $\theta$ and scenario scen

first year of availability for DM schemes

first year of the planning horizon average annual scenario duration in number of weeks. cost to inject flow at infeasible WRZs (infeasibility flow procedure) discount rate 


\section{Binary Variables}

$A S_{i, t} \quad 1$ if source $i$ is active during year $t, 0$ otherwise.

$A L_{i, j, t} \quad 1$ if link $i, j$ is active during year $t, 0$ otherwise.

$F S_{i, t} \quad 1$ at first year $t$ of activation of selected schemes $i, 0$ otherwise.

$F L_{i, j, t} \quad 1$ at first year $t$ of activation of selected links $i, j, 0$ otherwise.

\section{Positive Variables}

$S_{i, t, s c e n}$

$Q_{i, j, t, s c e n}$

Sut $t_{i, t, s c e n}$

$Q u t_{i, j, t, s c e n}$

$\alpha_{i, t, s c e n}$

INFEAS_FLOW supply from source $i$ during year $t$ and scenario scen to meet the WRZ total demand which is equal to the WRZ distribution input plus target headroom.

supply from node $i$ to node $j$ during year $t$ and scenario scen to meet the WRZ total demand which is equal to the WRZ distribution input plus target headroom.

supply from source $i$ during year $t$ and scenario scen to meet the WRZ distribution input (target headroom is not included in the mass balance equation)

flow from node $i$ to node $j$ during year $t$ and scenario scen to meet the WRZ distribution input (target headroom is not included in the mass balance equation)

demand satisfaction level for node $i$ during year $t$ and scenario scen. It has values between zero and one.

fictitious flow that can be injected to the infeasible WRZs during year $t$ and scenario scen.

\section{Appendix B. Calculation of Annualised Costs}

1. Annualised financial costs $\left(a f c c s_{i}, a f c c l_{i, j}\right)$ are calculated in the following way. Financial costs include: capital investments, environmental and social costs for optional sources (both supply-side and DM schemes) and new links. Undiscounted financial costs for optional sources and links $\left(\right.$ caps $_{i}$, capl $\left._{i, j}\right)$ are spread over the construction period of the assets $\left(c p s_{i}\right.$ for supply-side nodes and DM measures and $c p l_{i, j}$ for links). This provides annual cash flows whose future value is then evaluated at the end of the construction period:

$$
\begin{gathered}
f \operatorname{ccs}_{i}=\sum_{t t=0}^{c p s-1} \frac{\operatorname{caps}_{i}}{c p s_{i}} \times\left(1+i_{c}\right)^{t t} \quad \forall i \in O P T S O U \\
f c c l_{i, j}=\sum_{t t=0}^{c p l-1} \frac{c a p l_{i, j}}{c p l_{i, j}} \times\left(1+i_{c}\right)^{t t} \quad \forall(i, j) \in L F T
\end{gathered}
$$

In the equations above $i_{c}$ is the interest rate and $t t$ is an annual time index for the construction period.

2. Future capital costs are then annualised using: 


$$
\begin{gathered}
a f c c s_{i}=f c c s_{i} \times \frac{i_{c}\left(1+i_{c}\right)^{n s_{i}}}{\left(1+i_{c}\right)^{n s_{i}}-1} \quad \forall i \in O P T S O U \\
\operatorname{afccl}_{i, j}=f c c l_{i, j} \times \frac{i_{c}\left(1+i_{c}\right)^{n l_{i, j}}}{\left(1+i_{c}\right)^{n l_{i, j}}-1} \quad \forall(i, j) \in L F T
\end{gathered}
$$

where $n s_{i}$ is the average asset life of scheme $i, n l_{i, j}$ the average asset life of link $i, j$. The equations above implies the model only considers annualised costs during the planning horizon and does not consider capital costs to be incurred beyond the planning horizon.

\section{Appendix C. Interdependency Constraint Equations}

\section{C.1 Ratchet Constraints}

Ratchet constraints can be used to impose a monotonically (consistently) increasing usage of links and supply schemes during the planning horizon. They are usually implemented to discourage the use of an option during only a part of the planning period. This constraint is rarely used except when requested for strategic reasons.

$$
\begin{gathered}
S_{i, t+1, \text { scen }} \geq S_{i, t, \text { scen }} \quad \forall \text { scen } \in S C E N, i \in S R C, t<\text { tmax }-1 \\
Q_{i, j, t+1, \text { scen }} \geq Q_{i, j, t, \text { scen }} \quad \forall \text { scen } \in S C E N,(i, j) \in L R C, t<\text { tmax }-1
\end{gathered}
$$

In the equations ( $\mathrm{C} 1$ and $\mathrm{C} 2) S R C$ and $I R C$ are subsets used to identify those nodes and links that are subject to ratchet constraints.

\section{C.2 Start Date Constraints}

Some of the optional nodes and links can be available only after a certain year $\eta \in T$ :

$$
\begin{aligned}
& A S_{i, t}=0 \quad \forall i \in O P T S O U, t<\eta \\
& A L_{i, j, t}=0 \quad \forall(i, j) \in L F T, t<\eta
\end{aligned}
$$

\section{3 Continuity Constraints}

Continuity or 'irreversibility' constraints maintain the activation of binary variables $\left(A S_{i, t}\right.$ $\left.A L_{i, j, t}\right)$ at a value of one once a scheme is selected as most schemes cannot be 'un-built' later on to save costs.

$$
\begin{aligned}
& A S_{i, t+1} \geq A S_{i, t} \quad \forall i \in O P T S O U, t \leq(\text { tmax }-1) \\
& A L_{i, j, t+1} \geq A L_{i, j, t} \quad \forall(i, j) \in L F T, t \leq(\text { tmax }-1)
\end{aligned}
$$


C.4 Scheme Interdependence Constraints

\section{C.4.1 Mutually Exclusive Constraints}

'Mutually exclusive' constraints apply when only one supply node or link can be implemented from a set of optional nodes $z$ selected from set $I$ and $(i, j)$ links selected from set $C O N$.

If we define MUT_SET as a set composed by the mutually exclusive equations $\left(M U T \_S E T=\{e q: e q\right.$ is an equation $\left.\}\right)$, this constraint can be written as:

$$
\sum_{z} A S_{z, t}+\sum_{i, j} A L_{i, j, t} \leq 1 \quad \forall t \in T, e q \in M U T_{-} S E T
$$

with $z \in I$ and $(z, e q) \in M \_E X C L$, while links $(i, j) \in C O N$ and $(i, j, e q) \in N_{-} E X C L$. $M \_E X C L$ is a subset of the Cartesian product between a subset of nodes $z$ belonging to set $I$ and set MUT_SET, while $N_{-} E X C L$ is a subset of the Cartesian product between a subset of links $(i, j)$ belonging to set CON and set MUT_SET. $i, j, z$ are node indices and are used to refer to different nodes that belong to the same set $I$.

\section{C.4.2 Prerequisite Constraints (AND Condition)}

Prerequisite constraints (AND condition) assure that an optional source $z^{*} \in I$ (or link $(i, j) * \in C O N$ ) is allowed to be implemented only if a full set of prerequisite nodes $a$ selected from set $I$ and links $(b, c)$ selected from set $C O N$ has already been activated.

If we define PRERSET_AND as the set composed by the prerequisite equations (PRERSET_AND $=\{e q: e q$ is an equation $\})$, then this constraints can be written as:

$$
\begin{aligned}
& A S_{z^{*}, t} \leq \frac{\sum_{a} A S_{a, t}+\sum_{b, c} A L_{b, c, t}}{\text { num_Nright }_{\text {eq }}+\text { num_Lright }_{\text {eq }}} \quad \quad \forall t \in T, e q \in \text { PRERSET_AND }
\end{aligned}
$$

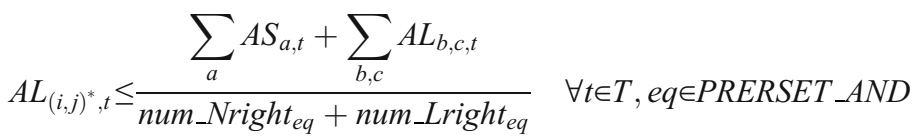

with $\mathrm{a} \in I$ and $(a, e q) \in P \_A N D$, while $(b, c) \in C O N$ and $(b, c, e q) \in N \_A N D$. $P \_A N D$ is a subset of the Cartesian product between a subset of nodes a belonging to set $I$ and set PRERSET_AND, while $N \_A N D$ is a subset of the Cartesian product between a specific subset of links $(i, j)$ belonging to set CON and set PRERSET_AND. Node $z^{*}$ and link $(i, j)^{*}$ change with the equation eq.

Num_Nright $t_{e q}$ and Num_Lright eq $_{-}$are the total number of elements (nodes and links respectively) contained in sets $P_{-} A N D$ and $N_{-} A N D$.

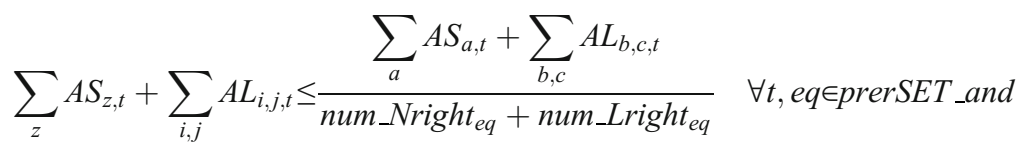




\section{C.4.3 Prerequisite Constraints (OR Condition)}

This constraint is used if the activation of at least one node $a$ selected from set $I$, or link $(b, c)$ selected from set $C O N$ is sufficient for the activation of node $z^{*}$ in year $t$ (equation $\mathrm{C} 10$ ) or link $(i, j) *$ in year $t$ (equation $\mathrm{C} 11$ ).

If we define PRERSET_OR as the set composed by the prerequisite (OR condition) equations (PRERSET_OR $=\{e q: e q$ is an equation $\}$ ), then the constraints can be written as:

$$
\begin{gathered}
A S_{z^{*}, t} \leq \sum_{a} A S_{a, t}+\sum_{b, c} A L_{b, c, t} \quad \forall t \in T, e q \in P R E R S E T \_O R \\
A L_{(i, j)^{*}, t} \leq \sum_{a} A S_{a, t}+\sum_{b, c} A L_{b, c, t} \quad \forall t \in T, e q \in \text { PRERSET_OR }
\end{gathered}
$$

with $a \in I$ and $(a, e q) \in P \_O R$, while $(b, c) \in C O N$ and $(b, c, e q) \in N \_O R$. $P \_$OR is a subset of the Cartesian product between a subset of nodes $a$ belonging to set $I$ and set PRERSET_OR, while $N \_O R$ is a subset of the Cartesian product between a subset of links $(i, j)$ belonging to set CON and set PRERSET_OR. Node $z^{*}$ and links $(i, j)^{*}$ change with the equation $e q$.

To help understand these equations, consider a first constraint (eql) with node 'optl' that cannot be activated if one or more among the following options has already been activated: node 'opt2', node 'opt3' and link 'WRZ1.WRZ3'. Equation C10 becomes:

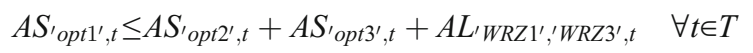

With $P \_O R=\{($ opt2,eq1 $),($ opt3,eq1 $)\}, N \_O R=\{($ WRZ1,WRZ2,eq1 $)\}$.

\section{C.4.4 Prerequisite Constraints with LAG TIME}

With this constraint a supply scheme $z^{*}$ is allowed to be activated at least $\delta$ years after the activation of another node $a^{*}$ selected from set I. If we define PRESET_LAG as the set composed by the prerequisite with $L A G$ time equations (PRESET_LAG $=\{e q: e q$ is an equation $\}$ ), then this constraint can be written as:

$$
\begin{gathered}
A S_{z^{*}, t}=0 \quad \forall t \leq \delta \\
A S_{z^{*}, t} \leq A S_{a^{*}, t-\delta} \quad \forall t>\delta
\end{gathered}
$$

where node $z^{*}$ and node $a^{*}$ change with the equation $e q$.

\section{C.4.5 Mutually Dependent Constraints}

These constraints force a specific node $z^{*}$ or link $(i, j)^{*}$ to be activated at the same time as a group of optional nodes $a$ selected from set $I$ and optional links $(b, c)$ selected from set $C O N$. 
If $D E P E N D E N T$ is a set composed of the mutually dependent equations (DEPENDENT = $\{e q: e q$ is an equation $\}$ ), then the dependency constraint can be written as:

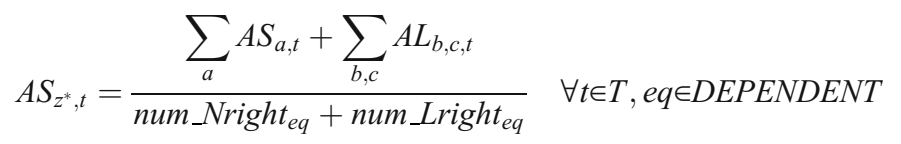

If applied to links the mutually dependent constraint becomes:

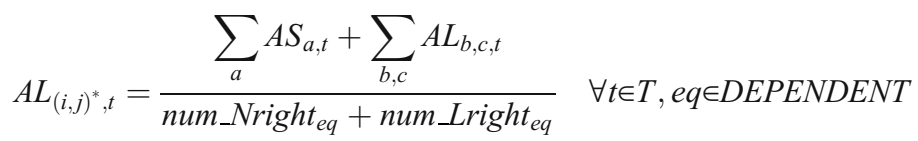

with $a \in I$ and $(a, e q) \in P \_D E P$ while $(b, c) \in C O N$ and $(b, c, e q) \in N \_D E P$.

$P \_D E P$ is a subset of the Cartesian product between a subset of nodes $a$ belonging to set $I$ and set DEPENDENT, while $N \_D E P$ is a subset of the Cartesian product between a subset of links $(i, j)$ belonging to set $C O N$ and set DEPENDENT. Node $z^{*}$ and link $(i, j)^{*}$ change with the equations $e q$.

\section{C.4.6 Capacity Connectivity Constraints}

These constraints force supply (in $\mathrm{Ml} / \mathrm{d}$ ) from a set of selected nodes $z$ and links $i, j$ to be less than total supply provided by other selected nodes $a$ and links $i, j$, plus an allowance (flow_par) which may vary depending on the scenario (set SCEN).

If $C A P A C I T Y$ is a set composed by the capacity connectivity equations (CAPACITY $=\{e q$ : $e q$ is an equation $\}$ ), then these constraints can be written as:

$$
\begin{aligned}
& \sum_{z} S_{z, t, \text { scen }}+\sum_{i, j} Q_{i, j, t, \text { scen }}= \\
& {\left[\sum_{a} S_{a, t, s c e n}+\sum_{b, c} Q_{b, c, t, s c e n}\right]+\text { flow }_{\text {par }} \text { eq,scen }} \\
& \forall t \in T, \text { scen } \in S C E N, e q \in C A P A C I T Y
\end{aligned}
$$

with $z \in I$ and $(z, e q) \in M \_C A P,(i, j) \in C O N$ and $(i, j, e q) \in Q_{-} C A P, a \in I$ and $(a, e q) \in P \_C A P$, while $(b, c) \in C O N$ and $(\overline{b, c}, e q) \in N_{-} C A P$.

$M \_C A P$ is a subset of the Cartesian product between a subset of nodes $z$ belonging to set $I$ and set CAPACITY, $Q_{-} C A P$ is a subset of the Cartesian product between specific links $(i, j)$ belonging to set $C O N$ and set CAPACITY, $P_{-} C A P$ is a subset of the Cartesian product between a subset of nodes $a$ belonging to set $I$ and set CAPACITY, and N_CAP is a subset of the Cartesian product between a specific subset of links $(b, c)$ belonging to set $C O N$ and set CAPACITY.

\section{References}

Barros MTL, Zambon RC, Barbosa PSF, Yeh WWG (2008) Planning and operation of large-scale water distribution systems with preemptive priorities. J Water Resour Plann Manag-Asce 134(3):247-256. doi:10.1061/(asce)0733-9496(2008)134:3(247)

Belli P, Anderson JR, Barnum HN, Dixon JA, Tan JP (2001) Economic analysis of investment operations. The World Bank, Washington D.C

Bellman RE (1957) Dynamic programming. Princeton University Press, Princeton, 0-486-42809-5 
Braga BPF, Conejo JGL, Becker L, Yeh WWG (1985) Capacity expansion of Sao-Paulo water-supply. J Water Resour Plann Manag-Asce 111(2):238-252

Brooke A, Kendrick D, Meeraus A, Raman R (2010) GAMS-A user's guide. GAMS Development Corporation, Washington DC

Chou FNF, Lee HC, Yeh WWG (2013) Effectiveness and efficiency of scheduling regional water resources projects. Water Resour Manag 27(3):665-693. doi:10.1007/s11269-012-0208-9

Climate Change Economics, Dpt. of Energy and Climate Change (2009) Carbon valuation in UK policy appraisal: a revised approach

Critchley R, Marshallsay D (2013) Water resources in the South East. Progress towards a shared water resources strategy in the South East of England. Phase 2B Report. UK

Dandy GC, McBean EA, Hutchinson BG (1984) A model for contrained optimum water pricing and capacity expansion. Water Resour Res 20(5):511-520

Deb K (2001) Multi-objective optimization using evolutionary algorithms, 1st edn. 978-0471873396, John Wiley \& Sons, LTD

EA (2005) Water resources in the South East economics of balancing supply and demand (EBSD) Modelling final report. UK

EA (2010) Water resources in the South East Group. Progress towards a shared water resources strategy in the South East of England. UK

EA, Ofwat, Defra, Welsh Government (2012a) Water resources planning guideline: the technical method and instructions. UK

EA, Ofwat, Defra, Welsh Government (2012b) Water resources planning guideline:Technical instructions for the water resources planning guideline supply-demand tables. UK

Harou JJ, Pinte D, Tilmant A, Rosenberg DE, Rheinheimer DE, Hansen K, Reed PM, Reynaud A, MedellinAzuara J, Pulido-Velazquez M, Matrosov E, Padula S, Zhu T (2010) An open-source model platform for water management that links models to a generic user-interface and data-manager. Paper presented at the International Environmental Modelling and Software Society (iEMSs) 2010 International Congress on Environmental Modelling and Software Modelling for Environment's Sake, Ottawa, Canada

Hsu NS, Cheng WC, Cheng WM, Wei CC, Yeh WWG (2008) Optimization and capacity expansion of a water distribution system. Adv Water Resour 31(5):776-786. doi:10.1016/j.advwatres.2008.01.009

Kim H-B, Hopkins LD (1995) Capacity expansion modelling of water supply in a planning support system for urban growth management. URISA J 8(1):58-66

Labadie JW (2004) Optimal operation of multireservoir systems: state-of-the-art review. J Water Resour Plann Manag-Asce 130(2):93-111. doi:10.1061/(asce)0733-9496(2004)130:2(93)

Labadie JW, Bode DA, Pineda AM (1986) Network model for decision-support in municipal raw watersupply. Water Resour Bull 22(6):927-940

Loucks DP, Van Beek E (2006) Water resources systems planning and management - an introduction to methods, models and applications. UNESCO, Paris

Loucks DP, Stedinger JR, Haith DA (1981) Water resources systems planning and analysis. Prentice-Hal, Englewood Cliffs, p 680 978-9231039980

Lund JR, Cai XM, Characklis GW (2006) Economic engineering of environmental and water resource systems. J Water Resour Plann Manag-Asce 132(6):399-402. doi:10.1061/(asce)07339496(2006)132:6(399)

Luo B, Maqsood I, Huang GH (2007) Planning water resources systems with interval stochastic dynamic programming. Water Resour Manag 21(6):997-1014. doi:10.1007/s11269-006-9069-4

Luss H (1982) Operations-research and capacity expansion problems - a survey. Oper Res 30(5):907-947

Mahmoud MR (2006) High dimension dynamic programming model for water resources expansion projects. Eng Optim 38(3):371-389. doi:10.1080/03052150600593218

Manne AS (1961) Capacity expansion and probabilistic growth. Econometrica 29(4):632-649

Manne AS (1967) Investments for capacity expansion: size, location, and time-phasing. MIT Press, Boston, p 237

Mays L (2005) Water resources systems management tools. McGraw-Hill, New York, p 320. 0071443819, 9780071443814

Ofwat (2009) Future water and sewerage charges 2010-15: final determination. Birmingham

Olaoghaire, Himmelblau (1974) Optimal expansion of a water resources system. In. Academic Press Inc, p 273

Revelle C (1999) Optimizing reservoir resources. Wiley, p 1800471188778

Savic DA, Walters GA (1997) Genetic algorithms for least-cost design of water distribution networks. J Water Resour Plann Manag-Asce 123(2):67-77. doi:10.1061/(asce)0733-9496(1997)123:2(67)

South East Water (2009) Water resources management plan: 2010-2035. Southern Water, Worthing, UK

Tu MY, Hsu NS, Yeh WWG (2003) Optimization of reservoir management and operation with hedging rules. J Water Resour Plann Manag-Asce 129(2):86-97. doi:10.1061/(asce)0733-9496(2003)129:2(286) 
UKWIR (2002a) The economic of balancing supply \& demand (EBSD) -Guidelines. London UKWIR (2002b) The economic of balancing supply \& demand (EBSD) -Main report. London UKWIR (2002c) An improved methodology for assessing headroom. London von Lany PH, Choudhury F, Hepworth N, Akande K (2013) Applying optimisation and uncertainty analysis to help develop an integrated water resources plan for South East England. Water Resour Manag 27(4):1111-1122. doi:10.1007/s11269-012-0121-2 